\title{
Jogo educacional "Conhecendo o Brasil"
}

\author{
Cleyciane A. Maciel, Elieder G. da Silveira, Stanelle Silveira, Pedro M. de Souza \\ ${ }^{1}$ Instituto de Ciências Exatas e Tecnológicas - Universidade Federal \\ de Viçosa campus Rio Paranaíba (UFV-CRP) \\ Rodovia MG-230, Km 07, Campus Universitário - CEP 38810-000 - \\ Rio Paranaíba - Minas Gerais - Brasil
}

\{cleycimaciel17, elieder93, profpedromoises\}@gmail.com, stanellejulle@hotmail.com

\begin{abstract}
This article aims to present the development and implementation of educational game Knowing Brazil. The game is based on geography subject and is intended for students of $6^{\circ}$ and $7^{\circ}$ grade of elementary school. With the aid of computer graphics and resources of the Unity3D platform, it offers a fun way of learning, as a complement to the theoretical subject.
\end{abstract}

Resumo. Este artigo tem como objetivo apresentar o desenvolvimento $e$ aplicação do jogo educacional Conhecendo o Brasil. O jogo é baseado na disciplina geografia e é voltado para alunos do $6^{\circ}$ e $7^{\circ}$ ano do ensino fundamental. Com o auxílio da computação gráfica e os recursos da plataforma Unity3D, propõe uma forma divertida de aprendizado, como um complemento as aulas teóricas da disciplina.

\section{Introdução}

Há tempos se buscam maneiras efetivas para o processo de ensino-aprendizagem, tendo que os seres humanos estão em um constante processo de evolução, é imprescindível o desenvolvimento de métodos que auxiliam a assimilação e propagação desse conhecimento. Nas últimas décadas o desenvolvimento de novas tecnologias - principalmente a evolução dos computadores - tem contribuído para criação de um vasto campo de opções sobre as técnicas de ensino-aprendizagem.

Os ambientes educacionais se tornaram mais dinâmicos, já que os profissionais da área da educação ganharam maior liberdade para disseminação do conhecimento e os alunos tem maior e melhor acesso aos conteúdos abordados. Aulas que antes se limitavam a extensas oratórias e quase nenhuma representação visual foram agregadas com importantes recursos da computação gráfica. A representação de imagens, vídeos e simulações computadorizadas deram origem a uma das grandes vertentes da computação gráfica em auxilio ao processo de ensino-aprendizagem, a utilização de jogos digitais.

Nesse sentido o jogo Conhecendo o Brasil pretende auxiliar as aulas de geografia, agregando experiências mais práticas e próximas da realidade, juntamente aos conceitos teóricos apresentados na disciplina.

O jogo propõe ao aluno uma viagem pelas diferentes regiões do país através um avatar, o mochileiro Nino, que o levará a conhecer as diversidades vegetais, climáticas, hídricas, culturais e territoriais do Brasil. Nessa viagem o aluno será inserido em senários 
V Congresso Brasileiro de Informática na Educação (CBIE 2016)

Anais dos Workshops do V Congresso Brasileiro de Informática na Educação (CBIE 2016)

ricos em detalhes que o ajudará a identificar as características de cada região do país segundo o conteúdo abordado na sala de aula.

As próximas seções irão apresentar as bases teóricas da aplicação, trabalhos relacionados, o desenvolvimento, os resultados da aplicação e as conclusões.

\section{Computação Gráfica}

A computação gráfica fornece um meio para um novo tipo de arte. Segundo a ISO citado por [Azevedo and Conci 2003], a definição de computação gráfica é: "um conjunto de ferramentas e técnicas para converter dados para ou de um dispositivo gráfico através do computador". Para [Santos et al. 2002], a computação gráfica pode ser definida como a área da Ciência da Computação responsável pela geração de imagens bi e tridimensionais usadas para diversos fins.

Essa ciência se enquadra nas subáreas: Síntese de Imagens, que se refere à criação visual do objeto a partir das especificações geométricas e visuais de seus componentes, o Processamento de Imagens, é manipulação da imagem digital e suas modificações e a Análise de Imagens, refere-se a analise das imagens digitais para obter características desejadas [Santos et al. 2002].

Hoje a presença da Computação Gráfica em nosso cotidiano é constante, pois está esta relacionada a quase todas as áreas do conhecimento humano. Entre as aplicações podem ser citado os Jogos, efeitos em filmes, desenhos animados e propagandas. Além dessas aplicações de entretenimento, ela é uma poderosa ciência aliada à medicina, pois está presente nos exames médicos, diagnósticos, estudos e planejamento de procedimentos. Em um outro extremo, a computação gráfica pode ser indispensável para uma boa Interface, projeto de sistemas e uma auxilio na educação [Santos et al. 2002].

Sendo assim, a computação gráfica será de grande importância para o desenvolvimento do jogo, pois é necessário que o aluno-jogador a se sinta atraído e cativado pelo jogo, seja pelo enredo ou pelo aspecto visual.

\section{Realidade Virtual}

Muitos autores, assim como [Netto et al. 2002] citam que a realidade virtual é um espelho do mundo real que oferece aos usuários, com auxilio de equipamentos, a possibilidade de interagir com o mundo virtual em três dimensões e com a sensação de tempo real.

Para [Ribeiro and Zorzal 2011] o usurário pode interagir com o mundo virtual através de janelas ou telas de projeção, técnica denominada não imersiva, ou pode interagir sendo inserido no mundo virtual através de dispositivos como capacete (HMD) e salas de multiprojeção, técnica denominada imersiva.

As características da realidade virtual a tornam extremamente relevante no contexto de um jogo digital educacional, pois pode levar o aluno/jogador em a um ambiente semelhante ao natural, criando uma sensação de realidade capaz de envolvê-lo. 
V Congresso Brasileiro de Informática na Educação (CBIE 2016)

Anais dos Workshops do V Congresso Brasileiro de Informática na Educação (CBIE 2016)

\section{Trabalho Relacionado}

Os jogos digitais tem se mostrado uma ferramenta interessante no auxilio ao ensinoaprendizagem devido seu conteúdo lúdico, atrativo e a grande variedade de temas que podem ser abordados. O jogo digital "Pedrinho e Pedrita conhecendo o mapa"(Figura 1) apresentado em [Dambros et al. 2015], aborda o ensino de noções básicas de cartografia através do incentivo lúdico de um pirata em busca de um tesouro. O jogador precisa responder questões relacionadas as noções básicas de cartografia, que vão sendo dificultadas ao longo das fases, com o objetivo de encontrar um tesouro.

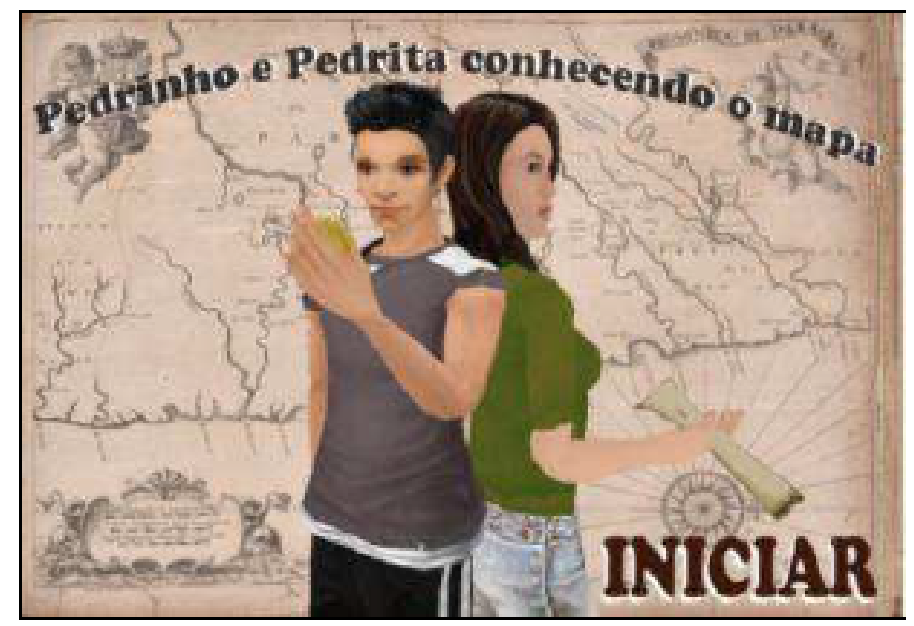

Figura 1. Tela Inicial - "Pedrinho e Pedrita conhecendo o mapa"

[Dambros et al. 2015]

Assim como em "Pedrinho e Pedrita conhecendo o mapa", o jogo Conhecendo o Brasil leva o aluno/jogador 'a praticar seus conhecimentos através de questões presentes no jogo, que o ajudaram a passar de fase. Porem seus objetivos se divergem, em quanto o primeiro explora a geografia através do aprendizado de cartografia básica o segundo busca enriquecer o conhecimento dos alunos/jogadores em relação as diversidades vegetais, climáticas, hídricas, culturais e territoriais do Brasil.

\section{Metodologia}

O desenvolvimento desse projeto foi norteado pelo processo de Desenvolvimento de Sistemas de Realidade Virtual (SRV) apresentado em [Tori et al. 2006] . O processo se baseia nos modelos ágeis de desenvolvimento iterativo e se divide em cinco etapas: Análise de Requisitos, Projeto, Implementação, Avaliação e Implantação.

$\mathrm{Na}$ etapa de análise de requisitos são definidas as características do projeto, ou seja, são definidos os requisitos do jogo como seus devidos objetivos e de que forma o usuário interage com o sistema. No caso do jogo Conhecendo do Brasil são explorados assuntos referentes a disciplina geografia e o aluno/jogador pode percorrer os cenários de cada fase do jogo, transitando em todos os sentidos do cenário em busca de perguntas relacionadas a respectiva região do país.

Já a etapa do projeto tem como principal objetivo especificar os dispositivos de entrada, saída, hardware, software, comportamentos e interações do projeto 
V Congresso Brasileiro de Informática na Educação (CBIE 2016)

Anais dos Workshops do V Congresso Brasileiro de Informática na Educação (CBIE 2016)

[Tori et al. 2006]. Conhecendo o Brasil utiliza-se dos recursos de entrada mouse e teclado para iteração com o avatar do jogo, e de recursos de saída com o monitor(imagens do jogo) e caixa de som, para execução da trilha sonora.

A implementação do jogo foi desenvolvida com a plataforma Unity3D, que possibilita a combinação de linguagens de programação, no caso, foi implementado em javascript e C\#. Sendo o principal objetivo da implementação utilizar-se dos recursos disponíveis para concretização do sistema, a fase efetiva o que foi planejados anteriormente [Tori et al. 2006].

É na fase de avaliação que o sistema é testado, verificando seu desempenho, usabilidade e eficácia, ou seja, é avaliado se o jogo cumpre o que foi proposto.

Por fim, com a implantação é verificado o ambiente de instalação do jogo. É necessário avaliar se os dispositivos em que o jogo serão instalados possuem os atributos necessários para seu devido funcionamento, se o ambiente possui estrutura necessária para suportar o publico alvo e se haverá condições do jogo alcançar seus objetivos propostos.

A cada iteração do projeto são construídas versões, onde as fases são revisadas, respectivamente avaliadas e corrigidas, facilitando a participação do usuário na construção dessas versões [Tori et al. 2006].

\section{Descrição do Jogo}

Com intuito de auxiliar os alunos na disciplina de geografia e despertar seu interesse para conhecer o Brasil, foram selecionados os principais aspectos geográficos do país para compor os enredo do jogo "Conhecendo o Brasil".

O jogo apresenta menu principal, menu secundário, cenários e o quadro de perguntas. O menu principal como pode se visto na Figura 2 é composto por cinco botões que correspondem às fases disponíveis no jogo e representam os aspectos geográficos selecionados para o projeto.
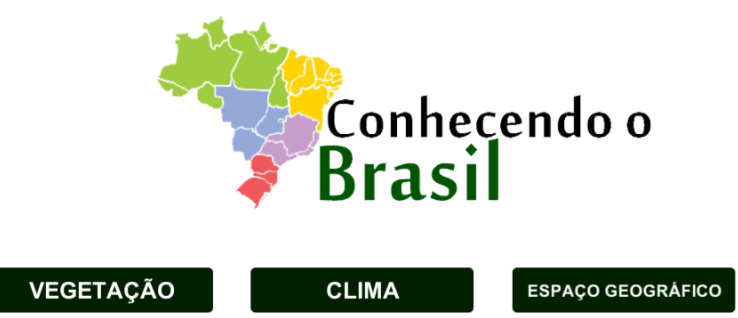

Figura 2. Menu Principal - "Conhecendo o Brasil"

Na fase "VEGETAÇÃO"o aluno/jogador "visitará"os diversos biomas do Brasil, passando por cada região do país, ele irá se deparar como questões relacionadas a vegetação local característica. O aluno/jogador será envolvido pelo enredo de cada cenário, entretanto, para responder as questões ele terá que possuir um conhecimento prévio da matéria. Com intuito de desenvolver sua curiosidade, o jogo apresenta ao 
V Congresso Brasileiro de Informática na Educação (CBIE 2016)

Anais dos Workshops do V Congresso Brasileiro de Informática na Educação (CBIE 2016)

aluno/jogador perguntas sobre as características das árvores e dos solos, além das demais distinções entre as vegetações de cada região.

Da mesma forma na fase "CLIMA"o aluno/jogador encontrará cenários e perguntas características de cada região, tais como as distinções climáticas nacionais mardas por cada estação do ano.

Através da fase "HIDROGRAFIA"o aluno/jogador será conscientizado das vantagens, desvantagens, direitos e obrigações de um dos países com alguns dos maiores afluentes hidrográficos do mundo, além disso, poderá conhecer as riquezas hídricas de cada região do Brasil, como seus rios e bacias hidrográficas.

Com um país tão diversificado, a fase "CULTURA"levará o aluno/jogador a uma viagem marcada por musicas, danças, comidas, moda e diversos características culturais de cada região. Além disso, através da fase “ESPAÇO GEOGRÁFICO”o aluno/jogador poderá compreender e visualizar como a população está distribuída em todo território nacional.

Todas as fases inicialmente são liberadas para que o aluno/jogador possa escolher qual tema irá jogar. Com a liberação de todas fases o professor poderá direcionar o aluno/jogador para o tema que está sendo estudado em sala de aula.

Ao escolher um tema (fase) clicando sobre um botão no menu principal o aluno/jogador será direcionado para o menu secundário (Figura 3). Nesse menu encontrase o mapa que representa o menu das subfases relacionadas ao tema escolhido. O mapa é inicializado com somente uma região colorida a qual o aluno/jogador deverá iniciar a fase. À medida em que o aluno/jogador finaliza a subfase, as regiões vão ganhado cores e sendo liberadas.

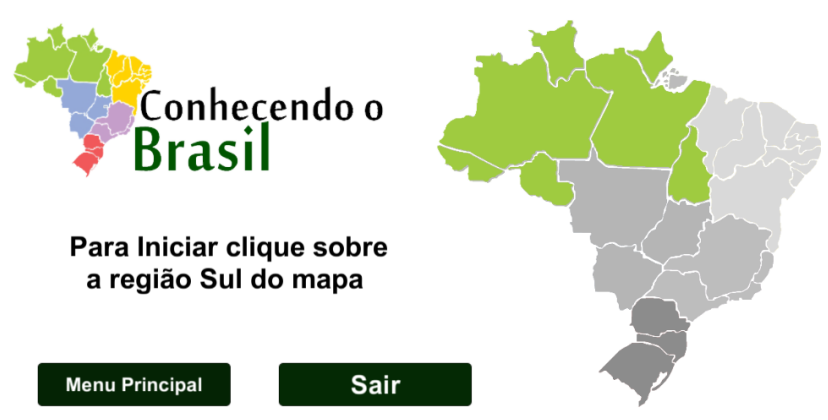

Figura 3. Menu Vegetação - "Conhecendo o Brasil”

As subfases são composta pelos cenários que possuem as características especificas da região, por exemplo, a subfase região nordeste da fase cultura, que é apresentada na Figura 4. Nessa subfase pode-se observar que os itens que compõe o cenário são a representação da cultura do nordeste como: o artesanato, o bumba meu boi, barraquinhas e a sombrinha que representa o frevo. Os itens além de compor o cenário são pistas para as possíveis perguntas que estão espalhadas pela fase. 
V Congresso Brasileiro de Informática na Educação (CBIE 2016)

Anais dos Workshops do V Congresso Brasileiro de Informática na Educação (CBIE 2016)

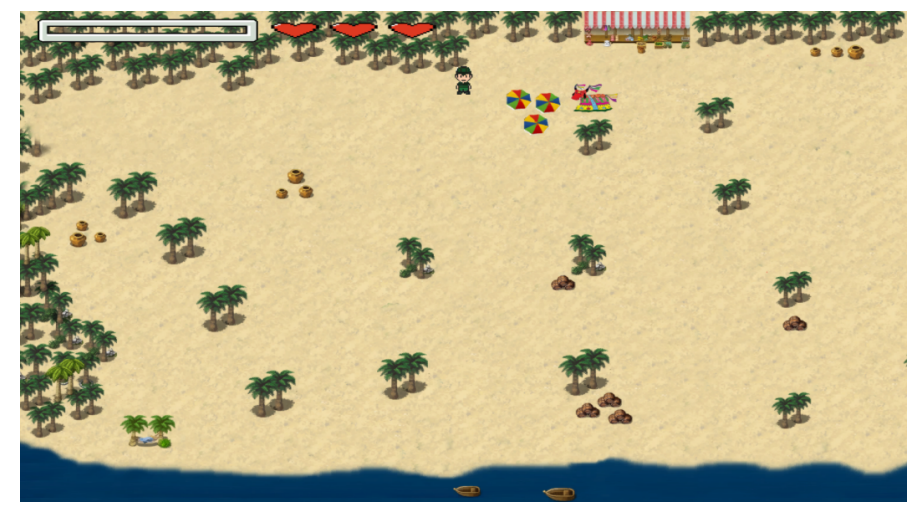

Figura 4. Nordeste Cultura - "Conhecendo o Brasil"

As perguntas aparecerão ao aluno/jogador a medida em que ele percorrer o cenário, já que estarão ocultas em determinados objetos e só serão acionadas quando o aluno/jogador passar por elas, quando isso ocorrer aparecerá um quadro contendo as questões da respectiva fase e região em o aluno/jogador estiver. O quadro da Figura 5 , apresenta uma das questões referentes a fase "VEGETAÇÂO"na região norte.

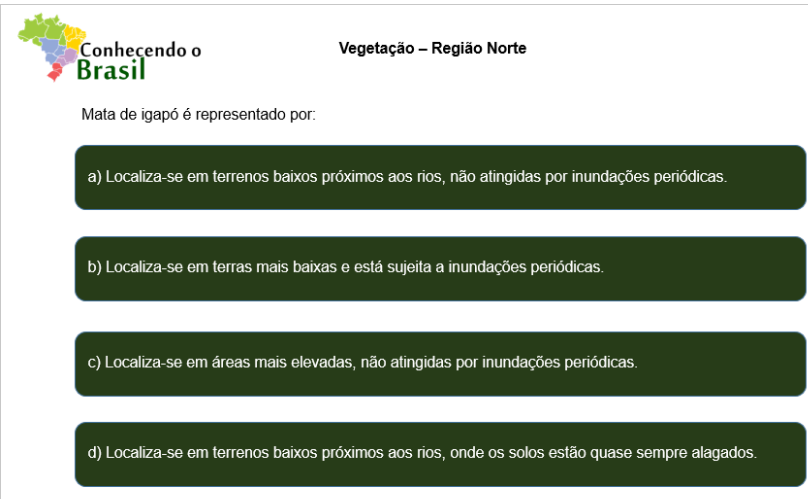

Figura 5. Quadro de Perguntas - Vegetação da Região Norte

Como o intuito deste trabalho é o auxilio ao aprendizado da disciplina geografia, ao clicar em uma das alternativas o aluno/jogador será direcionado a uma tela de respostas, caso a alternativa escolhida seja a errada, é apresentada tanto a alternativa correta, quanto a alternativa escolhida pelo aluno/jogador, assim como no quadro de respostas apresentado na Figura 6. Caso o aluno/jogador escolha a alternativa correta ele é parabenizado e também é apresentada a alternativa escolhida por ele, dessa forma, mesmo se o aluno errar a questão ele poderá adquirir conhecimento, além de poder comparar as respostas corretas com as erradas e confirmar suas respostas corretas. 
V Congresso Brasileiro de Informática na Educação (CBIE 2016)

Anais dos Workshops do V Congresso Brasileiro de Informática na Educação (CBIE 2016)

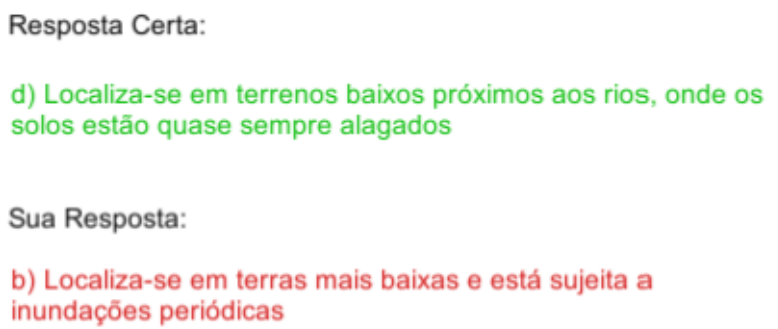

Figura 6. Quadro de Respostas - Vegetação da Região Norte

O aluno/jogador terá como personagem o Nino, que deverá explorar o cenário atrás de conhecimento. O conhecimento é associado a uma barra de progresso que cresce de acordo com as perguntas acertadas. Mas caso o aluno/jogador erre a pergunta, ele não perde o conhecimento, ou seja, a barra de progresso não decresce, mas ele perde vidas que são representadas por corações.

A medida que o aluno/jogador passa pelas fases vai adquirindo conhecimentos específicos sobre vegetação, clima, espaço geográfico, hidrografia e cultura ao mesmo tempo em que expande o seu conhecimento sobre o Brasil.

\section{Resultados}

O protótipo do jogo Conhecendo o Brasil foi apresentado na II Mostra de Jogos 2016, realizada no pavilhão de aulas da Universidade Federal de Viçosa - Campos Rio Paranaíba (UFV-CRP). O evento contou com a presença dos alunos do ensino Fundamental e discentes da UFV-CRP. Além de jogarem, 42 alunos responderam um questionário para avaliar o seu grau de satisfação em relação ao jogo. Com questionário de dez questões, os jogadores classificaram suas respostas em: 1 muito satisfeito, 2 insatisfeito, 3 pouco satisfeito, 4 satisfeito e 5 muito satisfeito.

Em questões que avaliam a clareza e objetividade do jogo como "Você acha que o jogo é auto descritivo? Ou seja, ele te informa como realizar as tarefas?", ou "O jogo é fácil de aprender?"e "Esse jogo pode ser utilizado por qualquer aluno, com pouca ou muita experiência no uso de computadores?", em que os resultados foram apresentados nas Figuras 7, 8 e 9 respectivamente, foram atribuídas notas 5 e 4, que indicam que avaliadores estavam satisfeitos ou muito satisfeitos com os aspectos avaliados, por mais de $80 \%$ dos avaliadores. Tais resultados demonstram que o jogo consegue passar a mensagem que deseja levando os usuários a realizarem ações necessárias pra sua execução. 
V Congresso Brasileiro de Informática na Educação (CBIE 2016)

Anais dos Workshops do V Congresso Brasileiro de Informática na Educação (CBIE 2016)

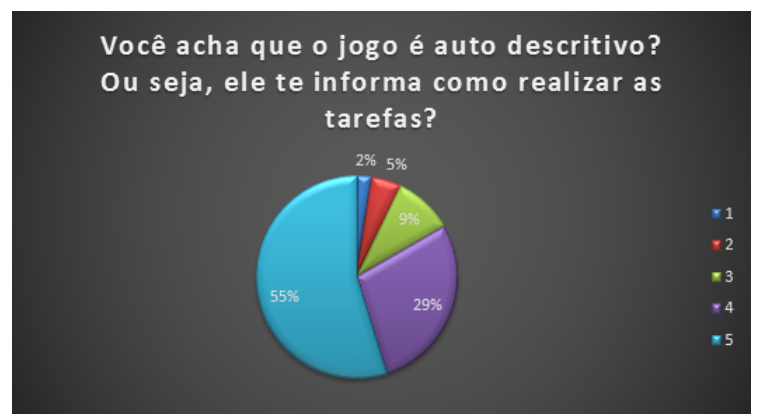

Figura 7. Questão 2 - Resultado da Avaliação do Grau de Satisfação

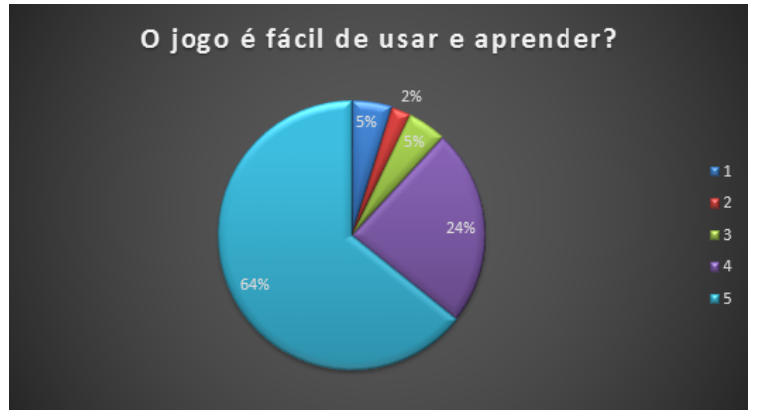

Figura 8. Questão 7 - Resultado da Avaliação do Grau de Satisfação.

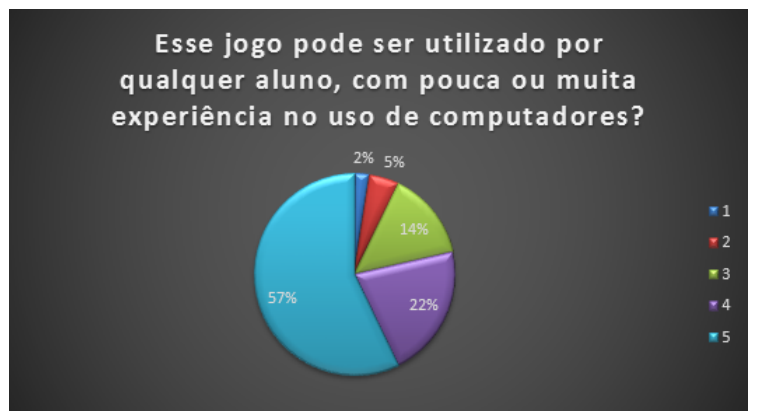

Figura 9. Questão 10 - Resultado da Avaliação do Grau de Satisfação.

Outro aspecto importante avaliado pelo questionário foi a usabilidade do jogo, os resultados apresentado nas Figuras 10 e 11, revelam que mais de 60\% dos jogadores afirmaram que não houve grandes dificuldades para interagir com o jogo. Além disso, estas questões demonstram que o manuseio e locomoção do personagem pelos cenários também é de fácil compreensão. 
V Congresso Brasileiro de Informática na Educação (CBIE 2016)

Anais dos Workshops do V Congresso Brasileiro de Informática na Educação (CBIE 2016)

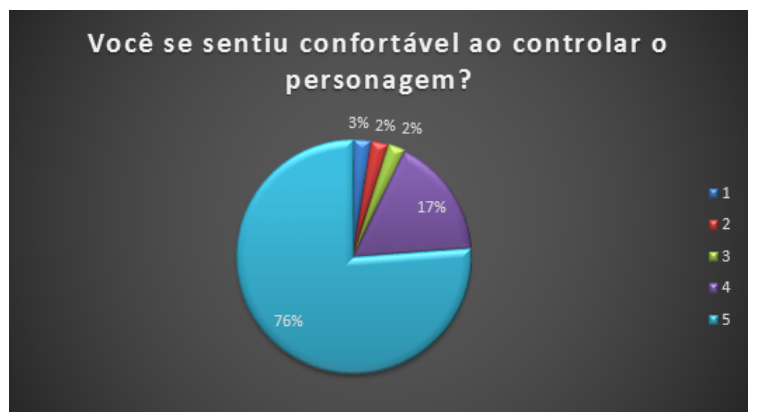

Figura 10. Questão 3 - Resultado da Avaliação do Grau de Satisfação.

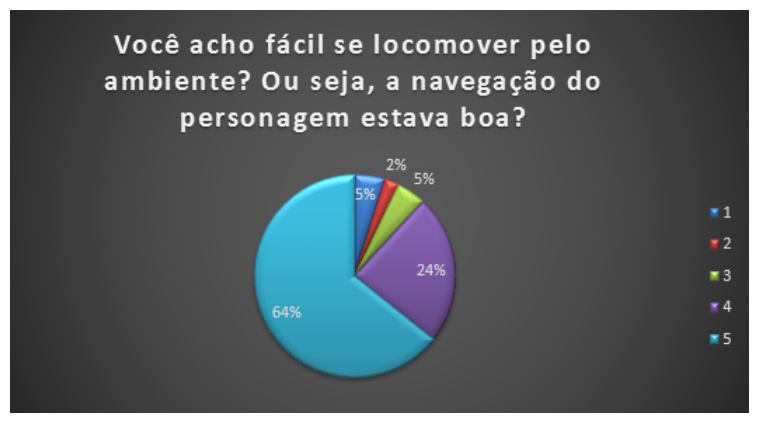

Figura 11. Questão 4 - Resultado da Avaliação do Grau de Satisfação.

Através do questionário também foi avaliado se o jogo está cumprindo com alguns dos objetivos propostos, com questões como "Me senti estimulado a aprender com o jogo?"e "O desing do jogo é atraente?", os jogadores puderam avaliar se o jogo realmente proporciona um aprendizado de forma lúdica e divertida. Os resultados das questões citada estão representados nas Figuras 12 e 13.

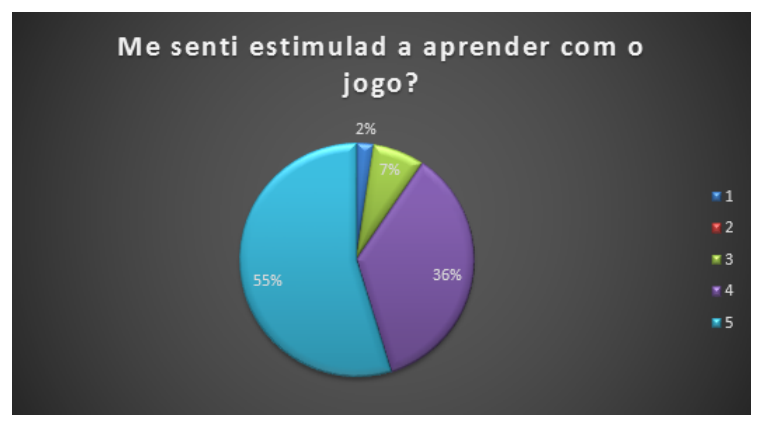

Figura 12. Questão 9 - Resultado da Avaliação do Grau de Satisfação. 
V Congresso Brasileiro de Informática na Educação (CBIE 2016)

Anais dos Workshops do V Congresso Brasileiro de Informática na Educação (CBIE 2016)

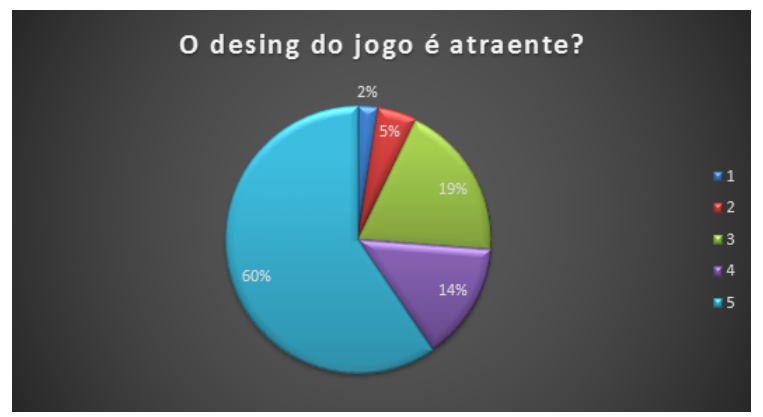

Figura 13. Questão 8 - Resultado da Avaliação do Grau de Satisfação.

\section{Conclusão}

De acordo como os resultados obtidos com a aplicação do jogo Conhecendo o Brasil, pode-se perceber que teve uma boa aceitação dos usuários, tendo em vista que em grande parte das questões os jogadores atribuíram 5 como resposta, ou seja, se mostraram muito satisfeitos com diversos aspectos do jogo.

Entretanto, há alguns aspectos que devem ser revistos para que o jogo alcance seus objetivos, tais como o incentivo ao aprendizado, a clareza e objetividade do jogo, o desing mais atrativo e algumas questões de usabilidade.

De forma geral, o jogo apresentou grande potencial pois apesar dos aspectos a serem aprimorados, cumpriu com o que foi propostos de forma satisfatória em quase todos os pontos avaliados no questionário. Para trabalhos futuros pretende-se aprimorar os pontos diagnosticados na avaliação para aprimoramento do jogo.

\section{Referências}

Azevedo, E. and Conci, A. (2003). Computação gráfica: teoria e prática. Elsevier.

Dambros, G., Cassol, R., and Bernardi, G. (2015). Jogo digital "pedrinho e pedrita conhecendo o mapa": avaliação por meio do método. GameFlow. Revista Tecnologias na Educação, 12.

Netto, A. V., Machado, L. d. S., and Oliveira, M. C. F. d. (2002). Realidade virtual-

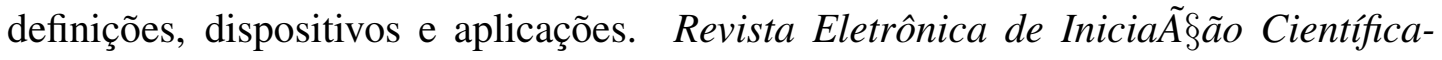
REIC. Ano II, 2.

Ribeiro, M. W. S. and Zorzal, E. R. (2011). Realidade virtual e aumentada: Aplicações e tendências. XIII Simpósio de Realidade Virtual e Aumentada, Uberlândia-MG-Brasil.

Santos, E. T., Zuffo, M. K., Netto, M. L., and de Deus Lopes, R. (2002). Computação gráfica: Estado da arte e a pesquisa na usp. Enciclopédia Encarta.

Tori, R., Kirner, C., and Siscoutto, R. A. (2006). Fundamentos e tecnologia de realidade virtual e aumentada. Editora SBC. 